\title{
La política de un solo hijo en China*
}

\section{Flora Botton Beja y Romer Cornejo Bustamante**}

Este artículo describe la política de planificación familiar en la República Popular China hasta 1979. La política de un solo hijo es enmarcada dentro de los rasgos más sobresalientes de la sociedad china, resaltando el papel de la estructura familiar y de los mecanismos tradicionales y contemporáneos de control social. Los autores demuestran que a pesar del éxito relativo de la campaña de planificación familiar en las áreas urbanas, el gobierno chino aún no ha alcanzado las metas que se propuso. Esta situación es explicada, en términos históricos, por los ritmos de la tasa de fecundidad, y en términos ideológicos, por el peso de una determinada estructura familiar tradicional. La investigación se basa fundamentalmente en fuentes chinas, así como en el propio trabajo de campo de los autores.

\section{Introducción}

Desde hace unos años, las políticas de población y las campañas de planificación familiar de China han llamado la atención en todo el mundo. Por un lado, el esfuerzo del país más poblado del mundo por limitar su crecimiento era visto con cierto alivio por aquellos a quienes preocupaba un aumento indiscriminado de la población mundial. Por otro lado, los éxitos iniciales que se percibían despertaban el interés de países que estaban comprometidos en un esfuerzo similar. El ejemplo de China era tanto más alentador cuando se consideraba que los patrones de familia tradicional en ese país de ninguna manera podían adecuarse a las nuevas reglas que se le imponían.

En la China tradicional y antes del establecimiento del régimen socialista de 1949, el ideal de familia en cuanto a su tamaño, función y estructura era el que avalaba el confucianismo; es decir, una familia extendida y numerosa, patrilocal, patrilineal y en la

* Este trabajo se realizó con material recolectado por los autores en un trabajo de campo en la República Popular China entre julio y noviembre de 1987. El trabajo de campo se llevó a cabo gracias a la colaboración de la Comisión Estatal de Educación de China, La Embajada de México en Beijing y la Universidad del Pueblo de China. En el procesamiento de los datos agradecemos el apoyo dado por la Dirección General de Planificación Familiar, de la Secretarfa de Salubridad y Asistencia.

** Centro de Estudios de Asia y África de El Colegio de México. 
que convivían varias generaciones bajo el mismo techo. Cada hijo debía cumplir con las obligaciones de conservar viva la memoria de sus antepasados por el culto ancestral y para ello era necesario que procreara muchos hijos varones.

Lo que sucedió después de 1949 fue, en primer lugar, un cambio a nivel oficial en el modelo de familia ideal. Aunque la aceptación de estos ideales de familia por la mayoría del pueblo chino es una revolución ideológica aún no realizada, ellos constituyen un punto de referencia de la política de planificación familiar (Chen, 1985, pp. 193-203). En las décadas de los años cincuenta y sesenta la familia modelo era presentada como una unidad doméstica que se constituía del esposo, la esposa y los hijos, con la obligación de cuidar de los parientes ancianos. En este modelo no se especificaba bien cuál sería el número ideal de los que conforman este hogar. No fue sino hasta la década de los setenta cuando se habló ya claramente de un modelo de familia pequeña con un máximo de dos hijos, y se inició una campaña nacional de educación y convencimiento. Finalmente, a partir de 1979, el modelo es el de la familia de un solo hijo y la campaña de planificación familiar se torna en algo más que eso; es una campaña de planificación de la población en la cual el gobierno no se limita a instruir sobre anticonceptivos y distribuirlos para que las parejas puedan, por voluntad propia, limitar su fecundidad, sino que se trata ya de intervenir en la reproducción humana para adecuarla a la producción material y así.poder crear más riqueza, mejorar los niveles de vida, y acelerar la modernización (Tien, 1985, pp. 132-133). En este contexto, el control de la fecundidad ya no es un asunto personal sino que atañe a toda la sociedad. Es tarea del Estado velar por el bienestar del pueblo, y la planificación de la población es su derecho y deber. Al imponer medidas draconianas, al exigir un sacrificio que afecta a todas las parejas chinas, el gobierno se expone a ser atacado y desafiado. Sin embargo, ante la urgencia del problema parecería que en China los líderies consideran que es peor la pasividad y la no acción.

La política de población en China, a pesar de dificultades y retrocesos, ha tenido resultados notables (véanse cuadros 1 y 2). No se conoce otro caso de una sociedad predominantemente campesina que haya logrado obtener una disminución tan notable de su tasa de natalidad en tan poco tiempo. El precio ha sido elevado y los problemas que se han suscitado van desde el enfrentamiento con patrones culturales milenarios, la intervención del Estado en lo más íntimo de la vida familiar, el sacrificio de un deseo natural de tener hijos, la evasión del registro de matrimonios y nacimientos, hasta el infanticidio femenino. 
CUADRO 1

Población ${ }^{1}$ (cifras de fin de año)(10 mil)

\begin{tabular}{|c|c|c|c|c|c|c|c|c|c|}
\hline \multirow[b]{3}{*}{ Año } & \multirow{3}{*}{$\begin{array}{c}\text { Total } \\
\text { de } \\
\text { población }\end{array}$} & \multicolumn{4}{|c|}{ Por sexo } & \multicolumn{4}{|c|}{ Por residencia } \\
\hline & & \multicolumn{2}{|c|}{ Hombres } & \multicolumn{2}{|c|}{ Mujeres } & \multicolumn{2}{|c|}{ Urbana $^{2}$} & \multicolumn{2}{|c|}{ Rural3 } \\
\hline & & Población & Porcentaje & Población & Porcentaje & Población & Porcentaje & Población & Porcentaje \\
\hline 1949 & 54167 & 28145 & 51.96 & 26022 & 48.04 & 5765 & 10.6 & 48402 & 89.4 \\
\hline 1950 & 55196 & 28669 & 51.94 & 26527 & 48.06 & 6169 & 11.2 & 49027 & 88.8 \\
\hline 1951 & 56300 & 29231 & 51.92 & 27069 & 48.08 & 6632 & 11.8 & 49668 & 88.2 \\
\hline 1952 & 57482 & 29833 & 51.90 & 27649 & 48.10 & 7163 & 12.5 & 50319 & 87.5 \\
\hline 1953 & 58796 & 30468 & 51.82 & 28328 & 48.18 & 7826 & 13.3 & 50970 & 86.7 \\
\hline 1954 & 60266 & 32242 & 51.84 & 29024 & 48.16 & 8249 & 13.7 & 52017 & 86.3 \\
\hline 1955 & 61465 & 31809 & 51.75 & 29656 & 48.25 & 8285 & 13.5 & 53180 & 86.5 \\
\hline 1956 & 62828 & 32536 & 51.79 & 30292 & 48.21 & 9185 & 14.6 & 53643 & 85.4 \\
\hline 1957 & 64653 & 33469 & 51.77 & 31184 & 48.23 & $9 \cdot 949$ & 15.4 & 54704 & 84.6 \\
\hline 1958 & 65994 & 34195 & 51.82 & 31799 & 48.18 & 10721 & 16.2 & 55273 & 83.8 \\
\hline 1959 & 67207 & 34890 & 51.91 & 32317 & 48.09 & 12371 & 18.4 & 54836 & 81.6 \\
\hline 1960 & 66207 & 34283 & 51.78 & 31924 & 48.22 & 13073 & 19.7 & 53134 & 80.3 \\
\hline 1961 & 65859 & 33880 & 51.44 & 31979 & 48.56 & 12707 & 19.3 & 53152 & 80.7 \\
\hline 1962 & 67295 & 34517 & 51.29 & 32778 & 48.71 & 11659 & 17.3 & 55636 & 82.7 \\
\hline 1963 & 69172 & 35533 & 51.37 & 33639 & 48.63 & 11646 & 16.8 & 57526 & 83.2 \\
\hline 1964 & 70499 & 36142 & 51.27 & 34357 & 48.73 & 12950 & 18.4 & 57549 & 81.6 \\
\hline 1965 & 72538 & 37128 & 51.18 & 35410 & 48.82 & 13045 & 18.0 & 59493 & 82.0 \\
\hline 1966 & 74542 & 38189 & 51.23 & 36353 & 48.77 & 13313 & 17.9 & 61229 & 82.1 \\
\hline 1967 & 76368 & 39115 & 51.22 & 37253 & 48.78 & 13548 & 17.7 & 62820 & 82.3 \\
\hline 1968 & 78534 & 40226 & 51.22 & 38308 & 48.78 & 13838 & 17.6 & 64696 & 82.4 \\
\hline
\end{tabular}


CUADRO 1

(continuación)

\begin{tabular}{|c|c|c|c|c|c|c|c|c|c|}
\hline \multirow[b]{3}{*}{ Año } & \multirow{3}{*}{$\begin{array}{c}\text { Total } \\
\text { de } \\
\text { población }\end{array}$} & \multicolumn{4}{|c|}{ Por sexo } & \multicolumn{4}{|c|}{ Por residencia } \\
\hline & & \multicolumn{2}{|c|}{ Hombres } & \multicolumn{2}{|c|}{ Mujeres } & \multicolumn{2}{|c|}{ Urbana $^{2}$} & \multicolumn{2}{|c|}{ Rural ${ }^{3}$} \\
\hline & & Población & Porcentaje & Población & Porcentaje & Población & Porcentaje & Población & Porcentaje \\
\hline 1969 & 80671 & 41289 & 51.18 & 39382 & 48.82 & 14117 & 17.5 & 66554 & 82.5 \\
\hline 1970 & 82992 & 42686 & 51.43 & 40306 & 48.57 & 14424 & 17.4 & 68568 & 82.6 \\
\hline 1971 & 85229 & 43819 & 51.41 & 41410 & 48.59 & 14711 & 17.3 & 70518 & 82.7 \\
\hline 1972 & 87177 & 44813 & 51.40 & 42364 & 48.60 & 14935 & 17.1 & 72242 & 82.9 \\
\hline 1973 & 89211 & 45876 & 51.42 & 43335 & 48.58 & 15345 & 17.2 & 73866 & 82.8 \\
\hline 1974 & 90859 & 46727 & 51.45 & 44132 & 48.57 & 15595 & 17.2 & 65264 & 82.8 \\
\hline 1975 & 92420 & 47564 & 51.47 & 44856 & 48.53 & 16030 & 17.3 & 76390 & 82.7 \\
\hline 1976 & 93717 & 48257 & 51.49 & 45460 & 48.51 & 16341 & 17.4 & 77376 & 82.6 \\
\hline 1977 & 94974 & 48908 & 51.50 & 46066 & 48.50 & 16669 & 17.6 & 78305 & 82.4 \\
\hline 1978 & 96259 & 49567 & 51.49 & 46692 & 48.51 & 17245 & 17.9 & 79014 & 82.1 \\
\hline 1979 & 97542 & 50192 & 51.46 & 47350 & 48.54 & 18495 & 19.0 & 79047 & 81.0 \\
\hline 1980 & 98705 & 50785 & 51.45 & 47920 & 48.55 & 19140 & 19.4 & 79565 & 80.6 \\
\hline 1981 & 100072 & 51519 & 51.48 & 48553 & 48.52 & 20171 & 20.2 & 79901 & 79.8 \\
\hline 1982 & 101541 & 52310 & 51.52 & 49231 & 48.48 & 21154 & 20.8 & 80387 & 79.2 \\
\hline 1983 & 102459 & 53865 & 51.58 & 49630 & 48.42 & 24126 & 23.5 & 78369 & 76.5 \\
\hline 1984 & 103475 & 53423 & 51.63 & 50052 & 48.37 & 33006 & 31.9 & 70469 & 68.1 \\
\hline 1985 & 104532 & 54011 & 51.67 & 50521 & 48.33 & 38244 & 36.6 & 66288 & 63.4 \\
\hline
\end{tabular}

${ }^{1}$ Las cifras en este cuadro son de la población de 29 provincias, regiones autónomas y municipios de China continental, incluyendo a las fuerzas armadas.

${ }^{2}$ Se refiere a la población que vive en áreas bajo la administración de ciudades grandes o medianas.

${ }^{3}$ Se refiere a la población de distritos excluyendo a los residentes de ciudades dentro del mismo distrito.

Tomado de State Statistical Bureau, Statistical Yearbook of China 1986, Hong Kong, Economic Information Agencv. 1986. p. 71 


\section{CUADRO 2}

Tasas de natalidad, tasas de mortalidad y crecimiento natural de la población (por mil)

\begin{tabular}{|c|c|c|c|c|c|c|c|c|c|}
\hline \multirow[b]{2}{*}{ Año } & \multicolumn{3}{|c|}{ Nacional } & \multicolumn{3}{|c|}{ Ciudad } & \multicolumn{3}{|c|}{ Distrito } \\
\hline & $\begin{array}{c}\text { Tasa de } \\
\text { nacimiento }\end{array}$ & $\begin{array}{l}\text { Tasa de } \\
\text { mortalidad }\end{array}$ & $\begin{array}{c}\text { Crecimiento } \\
\text { natural }\end{array}$ & $\begin{array}{c}\text { Tasa de } \\
\text { nacimiento }\end{array}$ & $\begin{array}{c}\text { Tasa de } \\
\text { mortalidad }\end{array}$ & $\begin{array}{l}\text { Crecimiento } \\
\text { natural }\end{array}$ & $\begin{array}{c}\text { Tasa de } \\
\text { nacimiento }\end{array}$ & $\begin{array}{l}\text { Tasa de } \\
\text { mortalidad }\end{array}$ & $\begin{array}{c}\text { Crecimiento } \\
\text { natural }\end{array}$ \\
\hline 1949 & 36.00 & 20.00 & 16.00 & & & & & & \\
\hline 1950 & 37.00 & 18.00 & 19.00 & & & & & & \\
\hline 1951 & 37.80 & 17.80 & 20.00 & & & & & & \\
\hline 1952 & 37.00 & 17.00 & 20.00 & & & & & & \\
\hline 1953 & 37.00 & $14 . c 0$ & 23.00 & & & & & & \\
\hline 195,4 & 37.97 & 13.18 & 24.79 & 42.45 & 8.07 & 34.38 & 37.51 & 13.7.1 & 23.80 \\
\hline 1955 & 32.60 & 12.28 & 20.32 & 40.67 & 9.30 & 31.37 & 31.74 & 12.60 & 19.14 \\
\hline 1956 & 31.90 & 11.40 & 20.50 & .37 .87 & 7.43 & 30.44 & 31.24 & 11.84 & 19.40 \\
\hline 1957 & 34.03 & 10.80 & 23.23 & 44.48 & 8.47 & 36.00 & 32.81 & 11.07 & 21.74 \\
\hline 1958 & 29.22 & 11.98 & 17.24 & 33.55 & 9.22 & 24.33 & 28.41 & 12.50 & 15.91 \\
\hline 1959 & 24.78 & 14.59 & 10.19 & 29.43 & 10.92 & 18.51 & 23.78 & 14.61 & 9.17 \\
\hline 1960 & 20.86 & 25.43 & -4.57 & 28.03 & 13.77 & 14.26 & 19.35 & 28.58 & -9.23 \\
\hline 1961 & 18.02 & 14.24 & 3.78 & 21.63 & 11.39 & 10.24 & 16.99 & 14.58 & 2.41 \\
\hline 1962 & 37.01 & 10.02 & 26.99 & 35.46 & 8.28 & 27.18 & 37.27 & 10.32 & 26.95 \\
\hline 1963 & 43.37 & 10.04 & 33.33 & 44.50 & 7.13 & 37.37 & 43.19 & 10.49 & 32.70 \\
\hline 1964 & 39.14 & 11.50 & 27.64 & 32.17 & 7.27 & 24.90 & 40.27 & 12.17 & 28.10 \\
\hline 1965 & 37.88 & 9.50 & 28.38 & 26.59 & 5.69 & 20.90 & 39.53 & 10.06 & 29.47 \\
\hline
\end{tabular}




\section{CUADRO 2}

(continuación)

\begin{tabular}{|c|c|c|c|c|c|c|c|c|c|}
\hline \multirow[b]{2}{*}{ Año } & \multicolumn{3}{|c|}{ Nacional } & \multicolumn{3}{|c|}{ Ciudad } & \multicolumn{3}{|c|}{ Distrito } \\
\hline & $\begin{array}{c}\text { Tasa de } \\
\text { nacimiento }\end{array}$ & $\begin{array}{l}\text { Tasa de } \\
\text { murtalidad }\end{array}$ & $\begin{array}{c}\text { Crecimiento } \\
\text { natural }\end{array}$ & $\begin{array}{c}\text { Tasa de } \\
\text { nacimiento }\end{array}$ & $\begin{array}{c}\text { Tasa de } \\
\text { mortalidad }\end{array}$ & $\begin{array}{c}\text { Crecimiento } \\
\text { natural }\end{array}$ & $\begin{array}{c}\text { Tasa de } \\
\text { nacimiento }\end{array}$ & $\begin{array}{c}\text { Tasa de } \\
\text { mortalidad }\end{array}$ & $\begin{array}{c}\text { Crecimiento } \\
\text { natural }\end{array}$ \\
\hline 1966 & 35.05 & 8.83 & 26.22 & $20 . \overline{85}$ & 5.59 & 15.26 & 36.71 & 9.47 & 27.24 \\
\hline 1967 & 33.96 & 8.43 & 25.53 & & & & & & \\
\hline 1968 & 35.59 & 8.21 & 27.38 & & & & & & \\
\hline 1969 & 34.11 & 8.03 & 26.08 & & & & & & \\
\hline 1970 & 33.43 & 7.60 & 25.83 & & & & & & \\
\hline 1971 & 30.65 & 7.32 & 23.33 & 21.30 & 5.35 & 15.95 & 31.86 & 7.57 & 24.29 \\
\hline 1972 & 29.77 & 7.61 & 22.16 & 19.30 & 5.29 & 14.01 & 31.19 & 7.93 & 23.26 \\
\hline 1973 & 27.93 & 7.04 & 10.89 & 17.35 & 4.96 & 12.39 & 29.36 & 7.33 & 22.03 \\
\hline 1974 & 24.82 & 7.34 & 17.48 & 14.50 & 5.24 & 9.26 & 26.23 & 7.63 & 18.60 \\
\hline 1975 & 23.01 & 7.32 & 15.69 & 14.71 & 5.39 & 9.32 & 24.17 & 7.59 & 16.58 \\
\hline 1976 & 19.91 & 7.25 & 12.66 & 13.12 & 6.60 & 6.52 & 20.85 & 7.35 & 13.50 \\
\hline 1977 & 18.93 & 6.87 & 12.06 & 13.38 & 5.51 & 7.87 & 19.70 & 7.06 & 12.64 \\
\hline 1978 & 18.25 & 6.25 & 12.00 & 13.56 & 5.12 & 8.44 & 18.91 & 6.42 & 12.49 \\
\hline 1979 & 17.82 & 6.21 & 11.61 & 13.67 & 5.07 & 8.60 & 18.43 & 6.39 & 12.04 \\
\hline 1980 & 18.21 & 6.34 & 11.87 & 14.17 & 5.48 & 8.69 & 18.82 & 6.47 & 12.35 \\
\hline 1981 & 20.91 & 6.36 & 14.55 & 16.45 & 5.14 & 11.31 & 21.55 & 6.53 & 15.02 \\
\hline 1982 & 21.09 & 6.60 & 14.49 & 18.24 & 5.28 & 12.96 & 21.97 & 7.00 & 14.97 \\
\hline 1983 & 18.62 & 7.08 & 11.54 & 15.99 & 5.92 & 10.07 & 19.89 & 7.69 & 12.20 \\
\hline 1984 & 17.50 & 6.69 & 10.81 & 15.00 & 5.86 & 9.14 & 17.90 & 6.73 & 11.17 \\
\hline 1985 & 17.80 & 6.57 & 11.23 & 14.02 & 5.96 & 8.06 & 19.17 & 6.66 & 12.51 \\
\hline
\end{tabular}

Tomado de State Statistical Bureau, op. cit., p. 72. 
¿Cuál ha sido el secreto del éxito obtenido contra tantas desventajas? Para algunos observadores la respuesta está en el carácter de los chinos, a quienes consideran más disciplinados y maleables que los occidentales. Рага quien conozca algo de China esto es una falacia: el pueblo chino es tanto o menos disciplinado que cualquiera otro en el mundo. Para otros, la explicación está en un régimen totalitario y un gobierno represivo que obtiene resultados pisoteando cualquier vestigio de libertad individual. Esto tampoco es del todo cierto. Si bien el gobierno chino tiene, por su misma estructura, mayores medios a su alcance para imponer ciertas políticas, esto no bastaría. Una característica peculiar de la tradición china es el énfasis dado a la educación. Desde épocas muy remotas se consideró que cualquier persuasión debería estar acompañada por un proceso educativo y que todo cambio debería efectuarse a través de la educación. El papel de la educación, tanto formal como informal, se hace aún más imperativo por la estructura de edad de la población china (véase el cuadro 3). Otro aspecto importante es la visión que los chinos tienen de sí mismos como seres con deberes sociales que tienen prioridad sobre las necesidades personales. En la China tradicional esto se limitaba al ámbito de la familia, del clan o de una clase social afín. La vigilancia y la presión del grupo era una manera de garantizar el cumplimiento del deber social. Esta característica de la sociedad china fue utilizada en varias ocasiones en la historia para establecer un sistema de vigilancia y de responsabilidad colectivas. El gobierno socialista ha tratado de inculcar la idea de un bien común que trasciende los intereses de familia y de clase y al mismo tiempo ha sabido utilizar los mecanismos de presión social y de responsabilidad colectiva haciendo de la planificación familiar asunto de todos: del comité de barrio, de la unidad de trabajo, de los cuadros a todos los niveles, de los familiares y de los amigos.

\section{Planificación familiar en los primeros 30 años de la República Popular China}

La preocupación de la República Popular China por el control del crecimiento de la población comenzó a mostrarse a partir del Censo de 1953, que informó de un aumento de la población de 541.67 millones en 1949 a 587.96 millones en 1953. En ese mismo año el gobierno central aprobó las medidas sobre contracepción y aborto propuestas por el Ministerio de Salud Pública (MSP). A fines de 1954 se realizó un foro sobre control de la natalidad en Beijing, 


\section{CUADRO 3}

Datos del Tercer Censo Nacional de Población, 1982.

Edad promedio y porcentaje de población vieja y joven por provincias

\begin{tabular}{|c|c|c|c|c|}
\hline Provincia & $\begin{array}{c}\text { Edad } \\
\text { promedio }{ }^{1} \\
\text { (año) }\end{array}$ & $\begin{array}{c}\text { Porcentaje } \\
\text { de población } \\
\text { vieja (más } \\
\text { de } 65 \text { años) }\end{array}$ & $\begin{array}{c}\text { Porcentaje } \\
\text { de población } \\
\text { joven } \\
\text { (0-14 años) }\end{array}$ & $\begin{array}{l}\text { Relación } \\
\text { entre las } \\
\text { tasas de } \\
\text { población } \\
\text { vieja y } \\
\text { joven } \\
\text { (población } \\
\text { joven = 100) }\end{array}$ \\
\hline Promedio nacional & 22.91 & 4.91 & 33.59 & 14.62 \\
\hline Shanghai & 29.23 & 7:43 & 18.16 & 40.88 \\
\hline Beijing: & 27.20 & 5.65 & 22.38 & 25.22 \\
\hline Tianjin & 26.67 & 5.58 & 24.18 & 23.07 \\
\hline Jiangsu & 25.53 & 5.55 & 28.98 & 19.14 \\
\hline Hebei & 24.72 & 5.67 & 30.79 & 18.42 \\
\hline Zhejiang & 24.70 & 5.76 & 29.30 & 19.65 \\
\hline Liaoning & 24.60 & 4.81 & 28.71 & 16.74 \\
\hline Shandong & 24.55 & 5.62 & 31.04 & 18.12 \\
\hline Sichuan & $23: 42$ & 4.68 & 34.38 & 13.60 \\
\hline Hubei & 23.05 & 5.00 & 32.72 & 15.27 \\
\hline Shanxi & 22.97 & 4.99 & 33.37 & 14.95 \\
\hline Shaanxi & 22.93 & 4.57 & 33.06 & 13.81 \\
\hline Guangdong & 22.53 & 5.43 & 33.91 & 16.02 \\
\hline Hunan & 22.50 & 4.97 & 33.94 & 14.66 \\
\hline Jilin . & 22.33 & 3.98 & 33.17 & 12.00 \\
\hline Henan & 22.25 & 5.23 & 34.90 & 14.98 \\
\hline Heilongjiang & 21.54 & 3.42 & 34.89 & 9.80 \\
\hline Tíbet & 21.45 & 4.60 & 36.61 & 12.58 \\
\hline Mongolia Interior & 21.11 & 3.61 & 35.52 & 10.17 \\
\hline Fujian & 20.68 & 4.38 & 36.50 & 12.00 \\
\hline Anhui & 20.17 & 4.08 & 36.15 & 11.30 \\
\hline Gansu & 20.10 & 3.49 & 36.32 & 9.61 \\
\hline Guangxi & 19.98 & 5.11 & 37.45 & 13.65 \\
\hline Jiangxi & 19.70 & $4: 50$ & 38.80 & 11.61 \\
\hline Xinjiang & 19.54 & 3.68 & 39.56 & 9.31 \\
\hline Yunnan & 19.40 & 4.50 & 39.17 & 11.49 \\
\hline Guizhou & 18.76 & 4,66 & 40.88 & 11.41 \\
\hline Qinghai & 18.54 & 2.69 & 40.56 & 6.64 \\
\hline Ningxia & 18.42 & 3.20 & 41.26 & 7.75 \\
\hline
\end{tabular}

\footnotetext{
${ }^{1}$ Tomado de State Statistical Bureau, op. cit., p. 81.
} 
después del cual se organizaron grupos de trabajo sobre control de natalidad y métodos. En marzo de 1955, el Comité Central del Partido Comunista emitió un documento sobre control de la población, donde se hacía un llamado al MSP para que colaborara en los programas de educación sobre control de la natalidad. Esta preocupación política era paralela a un debate entre intelectuales, donde sobresale Ma Yinchu, presidente de la Universidad de Beijing y principal defensor del control del crecimiento de la población. A mediados de 1957 esta campaña comenzó a ser duramente atacada como "neomalthusiana" y derechista (New China's Population, 1988, p. 217).

Los éxitos de esta primera campaña de control de la natalidad en China fueron pobres. En ello incidió fundamentalmente la paz y la prosperidad económica de los primeros años de la Revolución que hicieron elevar el índice de fecundidad considerablemente (véase en el cuadro 4 la tasa de fecundidad entre 1952 y 1955).

\section{CUADRO 4}

Tasa de fecundidad total de las mujeres de China en todo el país y en las áreas urbanas y rurales (1950-1985)

\begin{tabular}{lccccccc}
\hline Año & $\begin{array}{c}\text { Todo } \\
\text { el país }\end{array}$ & $\begin{array}{c}\text { Áreas } \\
\text { urbanas }\end{array}$ & $\begin{array}{c}\text { Áreas } \\
\text { rurales }\end{array}$ & $\begin{array}{c}\text { Año } \\
\text { el país }\end{array}$ & $\begin{array}{c}\text { Arreas } \\
\text { urbanas }\end{array}$ & $\begin{array}{c}\text { Áreas } \\
\text { rurales }\end{array}$ \\
\hline 1950 & 5.813 & 5.001 & 5.963 & 1967 & 5.313 & 2.905 & 5.847 \\
1951 & 5.699 & 4.719 & 5.904 & 1968 & 6.448 & 3.872 & 7.025 \\
1952 & 6.472 & 5.521 & 6.667 & 1969 & 5.723 & 3.299 & 6.263 \\
1953 & 6.049 & 5.402 & 6.183 & 1970 & 5.812 & 3.267 & 6.379 \\
1954 & 6.278 & 5.723 & 6.390 & 1971 & 5.442 & 2.882 & 6.011 \\
1955 & 6.261 & 5.665 & 6.391 & 1972 & 4.984 & 2.637 & 5.503 \\
1956 & 5.854 & 5.333 & 5.974 & 1973 & 4.539 & 2.387 & 5.008 \\
1957 & 6.405 & 5.943 & 6.504 & 1974 & 4.170 & 1.982 & 4.642 \\
1958 & 5.679 & 5.253 & 5.775 & 1975 & 3.571 & 1.782 & 3.951 \\
1959 & 4.303 & 4.172 & 4.323 & 1976 & 3.235 & 1.608 & 3.582 \\
1960 & 4.015 & 4.057 & 3.996 & 1977 & 2.844 & 1.574 & 3.116 \\
1961 & 3.287 & 2.982 & 3.349 & 1978 & 2.716 & 1.551 & 2.968 \\
1962 & 6.023 & 4.789 & 6.303 & 1979 & 2.745 & 1.373 & 3.045 \\
1963 & 7.502 & 6.207 & 7.784 & 1980 & 2.238 & 1.147 & 2.480 \\
1964 & 6.176 & 4.395 & 6.567 & 1981 & 2.631 & 1.390 & 2.910 \\
1965 & 6.076 & 3.749 & 6.597 & 1982 & 2.480 & 1.405 & 2.714 \\
1966 & 6.259 & 3.104 & 6.958 & $1984^{*}$ & 2.070 & & \\
& & & & $1985^{*}$ & 2.030 & & \\
\hline
\end{tabular}

* Tomado de New China's Population, Londres-Nueva York, China Financial and Economic Publishing House y MacMillan Publishing Company, 1988, p. 26. Fuente: "Análisis de la muestra de fecundidad del uno por mil de la población china." Población y Economía, 1983, pp. 152-166. 
A partir de 1958 y hasta 1962, la campaña de control de la natalidad perdió su ya insuficiente ímpetu inicial. El uso intensivo de mano de obra durante el "gran salto adelante", así como el reordenamiento de la población campesina de las comunas maquillaron las consecuencias del equilibrio precario entre la gran población de China y su escasez de recursos. Aunque los centros de control de la natalidad siguieron funcionando y hasta se inició el uso del dispositivo intrauterino (DIU), fueron muy pocos sus efectos sobre el control del crecimiento de la población. Por otro lado, la retórica política radical del movimiento presentaba a una gran población como la fuerza vital de la modernización acelerada. Los desastres naturales ocurridos en China entre 1959 y 1961 elevaron la tasa de mortalidad de $1.08 \%$ en 1957 a $2.54 \%$ en 1960 (Kaufman, 1983, pp. 19-21 y Peng, 1987, pp. 639-670).

Entre 1963 y 1966 se produjo la segunda campaña de control de la natalidad en China. Ahora ya no se hizo un debate intelectual como en la década anterior, sino que fue una decisión de alto nivel. Un aspecto importante de esta nueva campaña fue el papel de la educación, dirigida fundamentalmente a la población femenina y juvenil. La propaganda se centraba en los intereses individuales de las personas, en la consideración del matrimonio tardío y en el número de hijos. Se distribuían anticonceptivos y se daban otros servicios de planificación familiar como la esterilización y el aborto a parejas que no deseaban tener más hijos. Los trabajadores en planificación familiar a veces visitaban a las familias y las aconsejaban, pero era entendido que la decisión la tomaba la pareja. Sin embargo, según algunos autores' se impusieron sanciones económicas o presiones institucionales de otro tipo para hacer obligatorias las medidas, y hasta se usaron argumentos de puritanismo sexual. La organización de esta campaña recayó más en los cuadros políticos que en los médicos (Kaufman, 1983, p. 23).

Esta campaña tuvo un éxito relativo. Para 1965 se estimaba que entre 10 y $11 \%$ de las mujeres en edad de procrear usaban algún método anticonceptivo. Se puede decir que en este periodo los logros fueron fundamentalmente de la campaña de propaganda y educación más que de las técnicas; el control de la natalidad pasó a ser algo socialmente aceptable. El cambio de valores y la lucha contra la inhibición fueron los ejes de una campaña pensada a largo plazo. A pesar de lo antes dicho, el éxito de esta campaña no se reflejó drásticamente y de manera inmediata en la tasa de crecimiento de la población china, pues su efectividad entre los campesinos fue muy baja y por otra parte la tasa de mortalidad decreció (Kaufman, 1983, p, 26).

Entre 1966 y 1969 la Revolución Cultural afectó negativamente 
los esfuerzos por controlar la natalidad; los factores más importantes en este sentido fueron el temor de los cuadros a ser criticados si tomaban una posición muy radical al respecto y la desorganización institucional. En realidad el control de la natalidad no fue atacado duramente durante la Revolución Cultural; al contrario, continuaron las investigaciones sobre anticonceptivos orales y la primera píldora fue introducida en 1967. La tendencia de los jóvenes a casarse en ese momento, junto con la ausencia de propaganda sobre anticoncepción contribuyeron para que en esos años aumentara la tasa de natalidad (véase en el cuadro 4, el índice de fecundidad entre 1964 y 1968).

La tercera campaña de control de la natalidad se hizo después de los turbulentos años de la Revolución Cultural, entre 1969 y 1976. Fue entonces cuando los demográfos chinos señalaron que $50 \%$ de la población tenía menos de 20 años y $30 \%$ por ciento menos de 30 años de edad. Las altas tasas de natalidad alcanzadas entre mediados de las décadas de los cincuenta y los sesenta hacían prever que unos 20 millones de personas al año (entre 1979 y 1982 y 1987-1996) alcanzarían la edad de matrimonio. Si seguía el mismo promedio de 2.3 hijos por pareja, el total de la población llegaría a 1.3 mil millones en veinte años y 1.5 mil millones en cuarenta años. El costo que este crecimiento implicaría en dar educación, empleo y en satisfacer necesidades básicas era incalculable. La meta que se fijó fue reducir la tasa de crecimiento de la población a $2 \%$. El eslogan usado fue: "tarde, espaciados y pocos". En cuanto al número de hijos se propagó el siguiente dicho: "uno basta, dos puede ser, tres no has de querer" (Kaufman, 1983, pp. 2937; Banister, 1987, p. 184, y Croll, 1985, p. 21).

Desde 1969 se reinició la campaña de prensa con artículos sobre matrimonio tardío y distanciamiento de los hijos. La justificación ideológica se alejó formalmente de las ideas malthusianas; ya no se hablaba de sobrepoblación, sino que la campaña se justificaba diciendo que si la economía china era planificada, el crecimiento de la población también debía serlo, y se establecieron cuotas como en la producción económica. La planificación familiar era presentada como una meta nacional para el mejoramiento del nivel de vida de las masas. En esta etapa el esfuerzo se centró en innovaciones en los métodos anticonceptivos, en reorganización de la red médica, énfasis en las áreas rurales y la promoción de uno en uno.

En términos operativos, los elementos más importantes de esta campaña fueron la introducción de los médicos descalzos en el medio rural y la amplia disponibilidad de píldoras y DIU. Las intervenciones o medicamentos para el control de la natalidad 
eran gratis o de un valor nominal. Las mujeres que se esterilizaban tenían tres semanas de permiso pagadas por su trabajo; por aborto eran dos semanas, y por inserción de DIU dos días. A los hombres que se hacían vasectomía se les daba un día libre de trabajo; esto nunca fue presentado como "incentivo material" sino como compensación por el tiempo distraído y como recuperación física. Esta campaña, si bien tuvo resultados positivos, éstos fueron mediocres ante las necesidades del país (Kaufman, 1983, pp. 29-38 y cuadro 28 ).

\section{Política de un solo hjjo}

La política de un solo hijo está estrechamente ligada al esfuerzo de China, después de la muerte de Mao, por iniciar una nueva etapa de modernización socialista que fortalecería y transformaría al país. Se fijaron cuatro metas de modernización: la agricultura, la industria, la ciencia y la tecnología y la defensa. Sin embargo, ninguna de estas metas podría ser alcanzada sin una notable disminución de la población que, aun antes de comprobarlo con el Censo de 1982, se calculaba en más de 1000 millones (Croll, 1985, p. 23). La nueva meta fue reducir la tasa de crecimiento de la población a 1 por ciento.

En la Constitución enmendada en 1978 durante la Primera Sesión de la V Asamblea Popular Nacional, se estipula que el Estado estimula la planificación familiar, y ésta se convierte en un derecho y un deber de los ciudadanos. A partir de que las reformas comienzan a ponerse en práctica sistemáticamente en 1979, el control de la natalidad se incorpora al recién creado ordenamiento legal, así como a los planes quinquenales. En septiembre de 1980 el Comité Central del Partidó y el Consejo de Estado emitieron conjuntamente una carta abierta a todos los miembros del Partido y de la liga de la juventud para que consideraran el control del crecimiento de la población de China, y explicaban su urgencia e importancia. También hacían un llamado alentando a todas las parejas a tener un solo hijo. Un paso importante fue la nueva Ley de Matrimonio, aprobada en septiembre de 1980 en la III Sesión de la V Asamblea Popular Nacional, pues en ella se estipula que ambos cónyuges tienen el deber de practicar la planificación familiar y que debe estimularse el matrimonio tardío y la demora de tener hijos (Artículos 5 y 12, "Ley de Matrimonio de la República Popular China", 1980). De igual manera, la nueva Constitución adoptada en la V Sesión de la V Asamblea Popular Nacional en diciembre de 1982 estipula que el Estado promueve la planificación 
familiar y que el crecimiento de la población debe adecuarse al plan de desarrollo económico y social. También estipula que la planificación familiar es un deber de ambos cónyuges (Artículos 25 y 49, "Constitución de la República Popular China", 1982). Por otra parte, tanto el sexto (1981-1985) como el séptimo (1986-1990) Plan Quinquenal para el desarrollo económico y social colocan el control estricto del crecimiento de la población entre sus metas. La prácticà de esta nueva campaña de planificación familiar plantea a la población requerimientos como el matrimonio tardío, el distanciamiento entre el matrimonio y el primer hijo, así como entre posibles hijos sucesivos, y lo más importante, el tener un solo hijo.

Incorporar la planificación familiar en el plan nacional de población en China, significa una decisión del gobierno de apoderarse del control sobre decisiones de fecundidad y de reglamentar el comportamiento de la unidad reproductiva (la familia) a través de mecanismos de control político y de educación. La meta de la campaña de educación ha sido convencer al pueblo chino de que las condiciones "objetivas" del país no permiten que nazcan demasiados niños. Para eso hay que explicar la magnitud y seriedad del problema por todos los medios. Conocerlos bien deberá cambiar la mentalidad del pueblo y lo hará aceptar las medidas de control.

La política de un solo hijo, tomando en cuenta que existe $50 \%$ de probabilidad de que este hijo sea mujer, no fue fácilmente aceptada en China, sobre todo en el área rural, que constituye $64 \%$ de la población del país.' Por eso, conociendo los límites de la coerción bruta y no pudiendo esperar los efectos de la campaña de educación, el gobierno chino introdujo una serie de incentivos para acelerar la implantación de la campaña. A la vez, para que una campaña de esta índole pudiera tener éxito, debía haber también sanciones para desalentar tener un mayor número de hijos.

En general, los incentivos y las sanciones son de tipo económico. Se trata de estimular tener un solo hijo a través de la reducción del costo que ello implica, y a la vez hacer muy costosos los siguientes hijos. Los incentivos en el campo incluyen: 1) el pago de una suma global que podría ser, en una aldea rica, de $300 \mathrm{RMB}^{2}$ hasta $20 \mathrm{RMB}$ en una región pobre; 2) un subsidio mensual de unos $5 \mathrm{RMB}, 3$ ) asignar la misma cantidad de tierra para cultivo privado que se da a una familia con dos hijos; 4) darle al niño una

\footnotetext{
${ }^{1}$ Esta cifra está basada en la nueva división entre campo y ciudad hecha por los chinos, considerando a los "pequeños nuevos pueblos" recientemente fundados. Algunos autores prefieren seguir usando las cifras de $80 \%$ para el campo y $20 \%$ para la ciudad.

${ }^{2}$ Un RMB equivale a 0.26 dólares estadunidenses.
} 
ración de cereales de adulto; 5) prioridad y exención de pago para entrar en una guardería. En algunos casos se ofrece pagar gastos médicos. Si hay industrias rurales los padres del hijo único tienen prioridad en la distribución del empleo (Davin, 1985, p. 49 y Kane, 1985, p. 99). En varias regiones se aumenta el valor de los incentivos para los padres de niñas. En las ciudades se han.ofrecido una gran variedad de incentivos. En Tianjin, por ejemplo, se ofrece un subsidio de 5 RMB por mes hasta que el niño cumpla 14 años, guardería, tratamiento médico gratuito para toda la familia y vivienda más amplia. En Beijing, además de todo eso, se prometió ayudar a que los niños entren en escuelas de buen nivel y darles prioridad en empleos. En Shanghai, donde el nivel de fecundidad era ýa muy bajo al final de la década de los años setenta, se sumaron otras ventajas que favorecen al niño hasta el final de la preparatoria. En todos lados se conceden incapacidades de varios meses y hasta un año, por maternidad (Kane, 1985, pp. 98-99 y Kane, 1987, pp. 122-123).

Las sanciones consisten en lo contrario; es decir, en cobrar una suma de dinero a los interesados a fin de compensar al Estado por la carga que significa el nacimiento de otro niño. Se les quita un impuesto a los padres; la unidad de empleo puede retener de 5 a $10 \%$ del salario durante diez años por el tercer hijo y hasta 15 a $20 \%$ por un cuarto o quinto hijo; no se le asignan cuotas de cereales al niño y. los padres tienen que pagar todos los gastos médicos y educativos; no se tiene derecho ni a mayor espacio en vivienda ni a lote de tierra. Además, los padres no pueden ser promovidos ni recibir prestaciones (Croll, 1985, p. 30; Davin; 1985, p. 50 y Banister, 1987, pp. 184-186). En realidad los reglamentos no se refieren a los segundos nacimientos sino a partir del tercero. Las reglas establecidas dejan ver que un segundo hijo no es aconsejable pero no se aplican sanciones, mientras que el tercero debe ser evitado a toda costa (Croll, 1985, p. 28). Se insiste en que esta decisión debe de ser voluntaria y no coercitiva; sin embargo, como veremos más adelante, no siempre es así.

- El primer paso (y la única manera de poder cuantificar el resultado de la campaña) es el de hacer que las parejas firmen una "carta compromiso" de no tener más de un hijo y así obtener un certifícado que les dé el derecho de reclamar sus compensaciones. A pesar de que el gobierno chino había fijado como meta obtener la firma de $20 \%$ de parejas urbanas y $5 \%$ de parejas rurales para 1979 , al final del año se informó que se habían obtenido las de $29 \%$ en todo el país. En 1981, 33\% de las mujeres casadas en las áreas urbanas de entre 15 y 49 años tenían sólo un hijo. Otra cifra alentadora es que de ese grupo de mujeres, $78 \%$ habian firmado 
"cartas compromiso" de tener un solo hijo, comparado con $31 \%$ en el campo. En total, $14.4 \%$ de todas las mujeres casadas de ese grupo de edad en las áreas urbanas tenian el certificado.

La tasa de fecundidad general ha tenido un descenso sostenido desde 1971, pero ha sido más acentuado en las ciudades (véanse el cuadro 4 y la gráfica 1). El grado de socialización y de concientización que podríamos medir por la edad, así como por el nivel de educación y la ocupación, también se refleja en el índice de fecundidad general de las mujeres chinas. Entre las mujeres cuya ocupación requiere menos entrenamiento aumentan las tasas de segundos o más nacimientos (véase el cuadro 5); de igual manera, en la medida en que desciende el nivel de educación, aumenta el número de mujeres con más de dos hijos [véase el cuadro 6]. En cuanto a la edad, la relación también es clara en que el número de hijos aumenta entre personas con mayor edad. Esto fue comprobado por nuestra investigación, como veremos más adelante. ${ }^{3}$ Otro factor importante es el sexo del primer.hijo. En un estudio realizado en 1980 en un distrito' de la ciudad en Hefei, provincia de Anhui, se comprobó que entre los firmantes de la "carta compromiso", las dos terceras partes tenían un hijo varón (The Population Research Office, 1982).

El éxito alcanzado en 1981 no fue sostenido y en el campo se percibió una resistencia y una deserción cada día mayor. Parejas que habían firmado tenían más hijos y aun la restitución de lo ya obtenido o las multas no parecían importarles. Las razones están arraigadas tanto en la tradición como en la realidad actual china. Por un lado, el deseo de tener hijos varones por las razones tradicionales que pesan aún: manera de perpetuar la línea ancestral familiar, seguro contra la vejez, mano de obra, etc.; por el otro, el hecho de que los incentivos materiales para la planificación familiar en el campo no eran tan atractivos o no había manera de aplicar las sanciones. En las regiones pobres poco se podía ofrecer como recompensa, y lo que se les daba representaba un alto costo para la comunidad. Así, cuanto más éxitó tenía una campaña dentro de la comunidad rural, tanto mayor era lá carga sobre los escasos fondos disponibles. Además, el costo de ún niño en el campo no es $\tan$ alto a nivel individual. Un niño en el campo pronto se vuelve útil y trabaja contribuyendo a la economía familiar, y también constituye un seguro para la vejez en un país donde aún no

\footnotetext{
${ }^{3}$ Investigación realizada en seis ciudades: Beijing, Harbin, Xían, Jinan, Nanning y Shenzhen, de julio a noviembre de 1987. Para el presente trabajo sólo utilizamos 54 entrevistas grabadas, donde se indagó a profundidad sobre la situación en las familias de origen y de las familias actuales de los entrevistados.
} 
GRÁFICA 1

Tasa total de fecundidad en China (1950-1982)

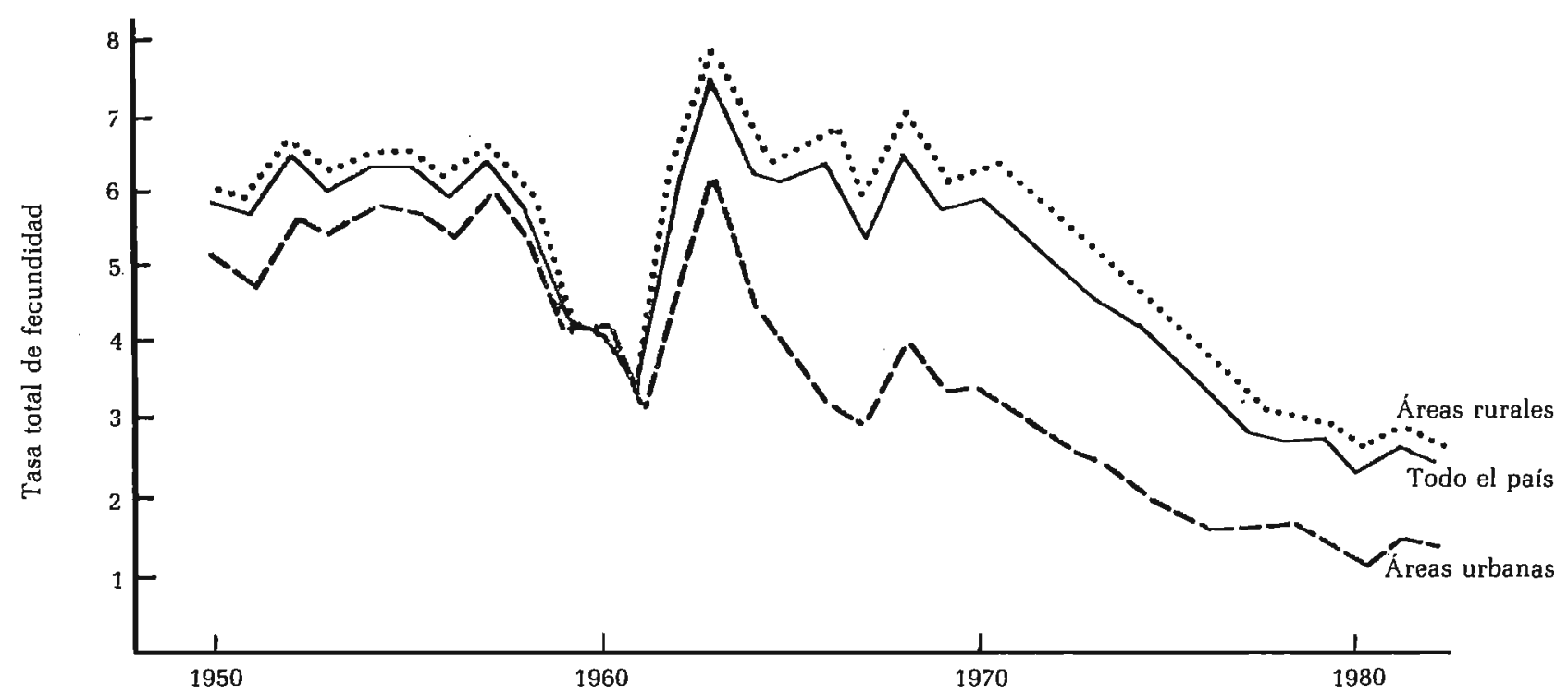

Fuente: "Análisis de la muestra de fecundidad del uno por mil de la población china" Población y Economía, 1983.

Tomado de New China's Population, op. cit., p. 86 
CUADRO 5

Tasa de fecundidad general y número de nacimientos en mujeres de diferentes ocupaciones (1981)

\begin{tabular}{|c|c|c|c|c|c|c|}
\hline Oçupación & $\begin{array}{c}\text { Tasa de } \\
\text { fecundidad } \\
\text { general* }\end{array}$ & $\begin{array}{c}\text { Primer } \\
\text { nacimiento } \\
\%\end{array}$ & $\begin{array}{c}\text { Segundo } \\
\text { nacimiento } \\
\%\end{array}$ & $\begin{array}{c}\text { Tercer } \\
\text { nacimiento } \\
\%\end{array}$ & $\begin{array}{c}\text { Cuarto } \\
\text { nacimiento } \\
\%\end{array}$ & $\begin{array}{l}\text { Quinto o más } \\
\text { nacimientos } \\
\%\end{array}$ \\
\hline Total & 85.32 & 47.94 & 25.02 & 12.73 & 6.64 & 7.67 \\
\hline Profesionales y técnicos & 67.78 & 81.50 & 14.96 & 2.24 & 0.67 & 0.63 \\
\hline \multicolumn{7}{|l|}{$\begin{array}{l}\text { Miembros responsables de órganos } \\
\text { estatales, partidos políticos, }\end{array}$} \\
\hline organismos y empresas populares & 32.89 & 83.76 & 13.52 & 1.73 & 0.49 & 0.50 \\
\hline Empleadas en oficinas & 61.18 & 89.26 & 9.46 & 0.89 & 0.25 & 0.14 \\
\hline \multicolumn{7}{|l|}{ Empleadas en establecimientos } \\
\hline comerciales & 64.85 & 82.25 & 13.57 & 2.55 & 0.90 & 0.73 \\
\hline Empleadas en servicio & 50.97 & 83.64 & 12.58 & 2.24 & 0.81 & 0.73 \\
\hline \multicolumn{7}{|l|}{ Trabajadoras en agricultura, } \\
\hline \multicolumn{7}{|l|}{ Trabajadoras en industrias, } \\
\hline transporte y otras obreras & 58.93 & 82.83 & 13.30 & 2.53 & 0.81 & 0.53 \\
\hline Varias trabajadoras manuales & 59.32 & 81.39 & 13.44 & 3.03 & 1.23 & 0.91 \\
\hline
\end{tabular}

Tomado de New China's Population, op. cit., p. 31.

Fuente: Censo de Población de China de 1982, Editorial de Estadísticas de China. 


\section{CUADRO 6}

Tasa de fecundidad general y número de nacimientos según el nivel de educación (1981)

\begin{tabular}{|c|c|c|c|c|c|c|}
\hline Nivel de educación & $\begin{array}{c}\text { Tasa de } \\
\text { fecundidad } \\
\text { general }^{*}\end{array}$ & $\begin{array}{c}\text { Primer } \\
\text { nacimiento } \\
0 \%\end{array}$ & $\begin{array}{c}\text { Segundo } \\
\text { nacimiento } \\
\%\end{array}$ & $\begin{array}{c}\text { Tercer } \\
\text { nacimiento } \\
\%\end{array}$ & $\begin{array}{c}\text { Cuarto } \\
\text { nacimiento } \\
0 \%\end{array}$ & $\begin{array}{c}\text { Quinto } \\
\text { nacimiento } \\
\%\end{array}$ \\
\hline Total & 82.36 & 47.25 & 25.60 & 12.93 & 6.64 & 7.58 \\
\hline Con educación & 75.66 & 57.74 & 24.19 & 9.71 & 4.41 & 3.95 \\
\hline Universitaria & 42.18 & 87.23 & 11.18 & 0.98 & 0.32 & 0.29 \\
\hline Preparatoria & 63.88 & 81.83 & 14.78 & 2.47 & 0.57 & 0.35 \\
\hline Secundaria & 67.43 & 70.32 & 20.46 & 5.73 & 1.97 & 1.52 \\
\hline Primaria & 86.25 & 44.33 & 28.76 & 13.85 & 6.80 & 6.26 \\
\hline Analfabeta o semianalfabeta & 94.50 & 32.02 & 27.64 & 17.60 & 9.88 & 12.86 \\
\hline
\end{tabular}

* "La tasa de fecundidad general se define como la razón, multiplicada por 1000 , entre el número total de nacimientos ocurridos durante un año en una población y el número medio de mujeres en edad de reproducción de esa misma población". Robert Carleton, Aspectos metodológicos y sociológicos de la fecundidad humana, Centro Latinoamericano de Demografía, Santiago de Chile, 1970, p. 25. Agradecemos a la profesora Beatriz Figueroa sus explicaciones sobre la manera de obtener la TFG.

Fuente: Censo de Población de China de 1982, Editorial de Estadísticas de China, 1985.

Tomado de New China's Population, op. cit., p. 30. 
existe un sistema de jubilación ni de cuidado para ancianos en forma generalizada en las zonas rurales (Davin, 1985, pp. 52-54).

También ha incidido en esta situación de resistencia el desmantelamiento de las comunas, lo cual deja al campo sin un órgano central de vigilancia, implantación de los programas y fuente de incentivos para el programa de control de la natalidad. La sustitución de las comunas por el sistema de responsabilidad familiar ha acentuado estos efectos. El elemento central del sistema de responsabilidad familiar consiste en ligar la remuneración a la producción. Para eso se ha retomado a la familia como la unidad productiva y contable con la que el Estado o su representante contrata, en forma diversa, la realización de una tarea. Esta forma de producción ha convertido a la familia campesina en una unidad autocentrada, es decir, en la unidad básica de producción y administración. Por el carácter particular de la institución familiar china estas nuevas relaciones están determinadas por relaciones de parentesco. Esto último ha llevado a la reproducción de patrones tradicionales en la división sexual del trabajo. Además es obvia la conclusión de que las familias numerosas tienen más ventajas para convertirse en prósperas. En este sentido, es evidente la contradicción entre: los efectos del sistema de résponsabilidad familiar y los intentos del gobierno chino por disminuir la tasa de natalidad en el campo. Tener más hijos, en especial del sexo masculino, es visto por el campesino como una ventaja para asegurar para su familia la mano de obra de ese hijo y la de su probable esposa. Además con el debilitamiento del sector colectivo-público de la economía se ha recargado a la familia con funciones de seguridad social, la más fuerte de las cuales es el cuidado de los ancianos ( $\mathrm{Wu}$, Zheng y Zhou, 1981, pp. 45-46).

La política de los órganos centrales de poder en relación con el control de la natalidad se hizo un poco más estricta en 1982 y 1983. A fines de 1982 se emitió una circular presionando fuertemente a las mujeres con un hijo para que usaran el DIU, o para que abortaran en caso de embarazos no autorizados; igualmente se insistía en la esterilización de uno de los cónyuges cuando las parejas tuvieran dos hijos o más. A pesar de las afirmaciones del gobierno sobre el carácter voluntario para aceptar y acatar la planificación familiar, y la insistencia en que los promotores deben saber persuadir, se sabe a ciencia cierta que se ejercieron presiones muy fuertes y que mucho del trabajo realizado fue de índole coercitiva. En primer lugar, hay que considerar la manera como se identifica a las parejas y la intromisión de la cual son objeto por parte de los trabajadores en planificación, las constantes visitas, las presiones, las críticas a las que están sometidas las parejas y 
sobre todo las mujeres, sobre quienes (a pesar de lo estipulado en la Ley de Matrimonio de 1980) recae la responsabilidad de la planificación familiar. A los jóvenes se les urge a casarse tarde, a los casados se les insta a no tener familia en seguida, a los que tienen un hijo se les vigila estrechamente y se averigua si han seguido métodos anticonceptivos y a las mujeres embarazadas, en muchos casos se les persigue y acosa hasta que deciden abortar. Otra manera de frenar la natalidad es insertando dispositivos de tal manera que no puedan ser extraídos más que por alguien especializado (Davin, 1985, p. 45; Banister, 1987, pp. 206-207 y Kane, 1987, p. 141). También se utiliza la esterilización, que por lo general es femenina. Si el DIU es el método anticonceptivo más popular, la esterilización está en segundo lugar y su índice aumenta considerablemente entre mujeres de 30 o más años (véase el cuadro 7). Según estadísticas de 1982, 35\% de las personas involucradas en la práctica antíconceptiva estaban esterilizadas; de ellas, $25 \%$ eran mujeres y $10 \%$ hombres (Banister, 1987, p. 215 y Chen, PiChao, 1985, p. 139).

\section{CUADRO 7}

Métodos anticonceptivos por grupos de edades (1982) (porcentaje de usuarios que practican algún método)

\begin{tabular}{lrrrrrrr}
\hline Método & $15-19$ & $20-24$ & $25-29$ & $30-34$ & $35-39$ & $40-44$ & $45-49$ \\
\hline DIU & 65.89 & 71.87 & 60.94 & 48.08 & 41.93 & 43.69 & 44.11 \\
$\begin{array}{l}\text { Ligadura de } \\
\text { trompas }\end{array}$ & 1.55 & 5.26 & 15.33 & 29.57 & 34.94 & 30.02 & 24.17 \\
Vasectomía & 0.39 & 1.26 & 5.58 & 9.85 & 12.43 & 13.16 & 15.97 \\
Píldora & 20.16 & 13.22 & 11.73 & 8.31 & 6.65 & 6.42 & 4.75 \\
Condón & 1.55 & 1.73 & 2.15 & 1.67 & 1.72 & 2.36 & 2.59 \\
Otros & 10.47 & $B .65$ & 4.26 & 2.51 & 2.33 & 4.35 & 8.40 \\
\hline
\end{tabular}

Fuente: Tomado de Judith Banister, China's Changing Population, Stanford, Stanford University Press, 1987, p. 173.

Otro aspecto de la planificación familiar que ha llevado al abuso y a la coerción es el intento del gobierno de involucrar a los cuadros locales en la ejecución de los programas de planificación. Se crea una gran presión sobre los cuadros para que cumplan con las cuotas impuestas y las metas fijadas. A estos cuadros se les transmite un doble mensaje: no usen coerción, pero cumplan con 
las metas. Para alentarlos a trabajar bien se les prometen incentivos materiales y su éxito es recompensado con remuneraciones en efectivo. Sin embargo, son sujetos a multas si fracasan. Estas circunstancias han resultado en abusos flagrantes de esterilizaciones y abortos forzados (Banister, 1987, pp. 197-199). Si bien el gobierno chino oficialmente no llama a que se emplee la coerción, esta situación se puede detectar a nivel provincial a través de artículos en los periódicos y en las amonestaciones de las autoridades. En una reunión de la Comisión Estatal de Planificación Familiar, un dirigente se pronunció contra los métodos simples y de coerción: "persuadir a la gente no es tarea fácil", dijo; sin embargo, insistió en que hicieran el esfuerzo (China Daily, 20 de abril de 1988).

Quizá el método utilizado por el gobierno chino para limitar el crecimiento de la población que ha tenido mejor acogida ha sido el matrimonio tardío (véase cuadro 8), pero este logro no puede ser atribuido solamente a la política oficial, sino que en ello también ha incidido la urbanización y la incorporación de la mujer al trabajo asalariado, por lo cual se observa una diferencia importante entre el campo y la ciudad. Sin embargo, en los últimos años se ha experimentado, aun en las áreas urbanas, un descenso relativo en la edad del matrimonio; esto puede verse como parte de la reciente liberalización de la vida social y política en China.

Como reacción al endurecimiento de la polf́tica oficial, a los abusos y a la coerción, hubo brotes de infanticidio femenino, así como de matrimonios ilegales. El infanticidio femenino, práctica conocida en casi toda sociedad patriarcal en el mundo, resurgió en China desde 1980, y aunque las sanciones del Estado son severas y la campaña de prensa para su erradicación ha sido importante no se puede decir que haya desaparecido (Renmin Ribao, 1 de abril de 1983 y Beijing Informa, núms. 17 y 38, 1983). Es una consecuencia extrema de una ideología patriarcal cuyas raíces están lejos de desaparecer (Benítez, 1986, pp. 398-412). Junto con las medidas punitivas, en China se ha propuesto también un trato preferencial para aquellos que tengan una hija única con el objeto de evitar abusos, pero esto aún no se practica en forma extendida (Yang y Wang, 1981, p. 57). Los matrimonios ilegales son aún más comunes. En un solo distrito de la provincia de Guangxi, entre 1981-1986, 6000 parejas nó legalizaron su matrimonio. Estas parejas, en la mitad de los casos, tenían edades por debajo del límite legal para casarse (China Daily, mayo 4, 1988). En la provincia de Jiangsu también se nota esta tendencia de matrimonios tempranos. Según una encuesta realizada por el Buró Estatal de Estadísticas en julio de 1987, 4.91\% de los hombres entre 15 y 21 años y de las mujeres entre 15 y 19 años, ya están casados; eso significa 


\section{CUADRO 8}

Edad promedio de las mujeres chinas para el primer matrimonio (1940-1982)

\begin{tabular}{lccccccc}
\hline Año & $\begin{array}{c}\text { Promedio } \\
\text { nácional }\end{array}$ & $\begin{array}{c}\text { Áreas } \\
\text { urbanas }\end{array}$ & $\begin{array}{c}\text { Áreas } \\
\text { rurales }\end{array}$ & Año & $\begin{array}{c}\text { Promedio } \\
\text { nacional }\end{array}$ & $\begin{array}{c}\text { Áreas } \\
\text { urbanas }\end{array}$ & $\begin{array}{c}\text { Áreas } \\
\text { rurales }\end{array}$ \\
\hline 1940 & 18.21 & 18.73 & 18.12 & 1962 & 19.61 & 21.49 & 19.27 \\
1941 & 18.21 & 18.88 & 18.09 & 1963 & 19.58 & 21.49 & 19.25 \\
1942 & 18.34 & 18.78 & 18.27 & 1964 & 19.55 & 22.04 & 19.17 \\
1943 & 18.41 & 19.39 & 18.22 & 1965 & 19.74 & 22.57 & 19.30 \\
1944 & 18.46 & 19.17 & 18.32 & 1966 & 19.86 & 22.86 & 19.44 \\
1945 & 18.60 & 19.35 & 18.45 & 1967 & 20.03 & 22.73 & 19.57 \\
1946 & 18.69 & 19.57 & 18.50 & 1968 & 20.17 & 22.62 & 19.73 \\
1947 & 18.53 & 19.21 & 18.40 & 1969 & 20.29 & 22.45 & 19.94 \\
1948 & 18.59 & 19.39 & 18.42 & 1970 & 20.19 & 22.38 & 19.89 \\
1949 & 18.57 & 19.16 & 18.44 & 1971 & 20.29 & 22.80 & 19.96 \\
1950 & 18.68 & 19.41 & 18.52 & 1972 & 20.56 & 23.23 & 20.22 \\
1951 & 18.69 & 19.43 & 18.54 & 1973 & 20.95 & 23.48 & 20.60 \\
1952 & 18.94 & 19.75 & 18.76 & 1974 & 21.38 & 23.79 & 20.99 \\
1953 & 18.94 & 19.85 & 18.71 & 1975 & 21.74 & 24.13 & 21.36 \\
1954 & 19.00 & 20.12 & 18.72 & 1976 & 22.30 & 24.61 & 21.90 \\
1955 & 19.07 & 20.28 & 18.81 & 1977 & 22.57 & 24.99 & 22.11 \\
1956 & 19.19 & 20.51 & 18.87 & 1978 & 22.83 & 25.10 & 22.41 \\
1957 & 19.23 & 20.40 & 18.90 & 1979 & 23.12 & 25.40 & 22.64 \\
1958 & 19.15 & 20.77 & 18.78 & 1980 & 23.05 & 25.19 & 22.54 \\
1959 & 19.35 & 20.81 & 19.01 & 1981 & 22.82 & 24.71 & 22.28 \\
1960 & 19.57 & 21.25 & 19.24 & 1982 & 22.66 & 24.93 & 22.07 \\
1961 & 19.70 & 21.46 & 19.40 & & & & \\
\hline
\end{tabular}

Fuente: Muestra de fecundidad del uno por mil de la población china. Datos proporcionados por el grupo encargado de la Comisión Estatal de Planifícación Familiar.

Tomado de New China's Population, op. cit., j. 137.

un aumento de $1.67 \%$ con respecto a 1982 [Beijing Review, núm. 49,1988, p. 28). Las razones, según un editorial, son el desequilibrio en el número de hombres y mujeres; como hay más hombres, los padres quieren asegurarse muy temprano que el hijo tendrá esposa. También inciden algunas reglas absurdas, como el necesitar hacer un depósito de 400 a $600 \mathrm{RMB}$ en el lugar de trabajo como garantía de que no se contraerá matrimonio y el costo elevado del examen médico pre-matrimonial exigido en algunos lugares [China Daily, 30 de mayo de 1988). Hay información de que en la provincia de Anhui $80 \%$ de los matrimonios son ilegales y se hacen a la usanza antigua por intercambio entre familias, a veces ven- 
diendo (por cantidades que fluctúan entre 800 a 3000 RMB) a las futuras esposas, cuando son aún nin̄as. En la misma región se han dado casos de matrimonios infantiles, de secuestros de mujeres, etc. (China Daily, 6 de julio de 1988.)

Las parejas que no registran su matrimonio tampoco entran en ningún plan de planificación familiar. Esto aumenta los embarazos no controlados y hace subir la tasa de natalidad y los niños nacidos de estas uniones no son registrados. Se habla de un millón de niños sin registro, o "niños negros" que pertenecen a estas parejas o a otras que evaden por varios medios ser detectados por los promotores y dan a luz lejos de sus lugares de residencia, con parteras cómplices o en hospitales que aceptan sobornos. Muchos obreros rurales migrantes (hay en la actualidad unos 50 millones) tienen hasta 5 o 6 hijos sin registrar (China Daily, 1 de julio de 1988). ¿Qué pasará con estos niños cuando necesiten entrar a la escuela y luego conseguir trabajo? En otros casos, cuando una pareja ha decidido tener más hijos y la mujer tiene un DIU se lo saca o se lo hace sacar de manera inexperta con graves consecuencias para su salud. Esto se conoce por las denuncias que aparecen en periódicos en los cuales se relatan casos.

Probablemente el descontento y la resistencia en las áreas rurales provocó un cambio de política que se inició con la remoción, en diciembre de 1983, del ministro encargado de la Comisión Estatal de Planificación Familiar. A principios de 1984 el Comité Central del Partido revisó la política de planificación familiar y el 13 de abril emitió el Documento Central núm. 7, que en general ha servido de guía para la planificación familiar desde entonces. El objetivo de ese documento fue restablecer la estrategia de la planificación familiar sobre bases más realistas, adecuadas y razonables para la gente, fácil de poner en práctica por los cuadros y capaz de lograr la meta del Partido de 1.2 mil millones de habitantes para fines del siglo. Ideológicamente, el Documento 7 justifica la planificación familiar en función de las grandes metas del país en cuanto al desarrollo de la economía, el mejoramiento del nivel de vida y el logro de las cuatro modernizaciones. En cuanto a la práctica política el Documento 7 critica la tendencia a imponer medidas uniformes a todas las parejas en todos los lugares y aboga por la flexibilidad sobre bases individuales y circunstancias cambiantes. En relación con la participación de la gente, el documento exige a los trabajadores de la planificación familiar que tengan una relación más estrecha con el pueblo, que tomen en cuenta sus necesidades, que les den asistencia práctica y les ayuden con los problemas concretos que están tras sus deseos de tener más hijos (Greenhalgh, 1986, pp. 492-495). 
El Documento 7 permite un segundo hijo a parejas rurales con "dificultades prácticas". Aunque un documento emitido a nivel central en 1984 sugería que inicialmente a $10 \%$ de las parejas rurales podía permitírseles un segundo hijo, primero la práctica y después una sanción oficial dejaron esta decisión a las instancias del gobierno locales. Por esta razón, las normas provinciales para tener un segundo o tercer hijo varían de acuerdo con las condiciones específicas de cada provincia. Greenhalgh registra siete situaciones básicas en las que se permite un segundo hijo en Anhui, Guangdong, Guangxi, Liaoning, Qinghai, Shaanxi y Shanghai. Esas condiciones son incapacidad física, ocupación peligrosa, pertenecer a un grupo étnico o especialmente privilegiado, el sexo del primer hijo, la preservación de la línea familiar y el permiso para que cada uno tenga su propio hijo. Dentro de esas condiciones generales hay casos específicos que varfan de región a región (Greenhalgh, 1986, pp. 496-497).

El Documento 7 también prohibió la "coerción y el dirigismo" y se establecieron tres normas: trabajo regular en vez de métodos de choque, contracepción en vez de abortos y propaganda y educación en vez de sanciones económicas (Yu, 1985, pp. 24-26). Igualmente hizo un llamado a no basarse solamente en el DIU (para mujeres con un hijo) y en la esterilización (para parejas con dos hijos o más), sino a ofrecer una gama más variada de anticonceptivos para que las parejas pudieran escoger el que mejor se adaptara a sus necesidades. El documento regresaba la responsabilidad de la campaña al nivel local, basándose en el sistema de responsabilidad. Al parecer, con algunos defectos, la política enunciada en este documento ha tenido buena acogida, pero se suscitó un alza de las tasas de nacimiento. En 1986 la tąsa de crecimiento natural de la población llegó a 14.08 por mil, la más elevada desde 1982 , en 1987 ésta se elevó a 14.95. La principal explicación para este aumento, que además es previsible que continúe, es la explosión de población que empezó en 1963 y se acentuó con los primeros años de la Revolución Cultural, pues los nacidos en ese momento ya entraron en la edad de procrear (China Daily, 19 de abril de 1988).

China se encuentra ante un dilema y una contradicción. La severidad de la campaña de planificación familiar dio resultados iniciales excelentes; sin embargo, la misma severidad provocó abusos y descontento que obligaron a una parte de la población a desafiar la ley y a cometer actos criminales. Por otro lado, cualquier relajamiento neutraliza todo lo logrado. El problema más grave aún está en el campo, por las razones ya explicadas, donde las consecuencias del relajamiento no se hicieron esperar. 
Según estadísticas oficiales, $40 \%$ de las mujeres rurales ha dado a luz a tres o más hijos en los últimos años. Para fines de $1986,70 \%$ de las aldeas de la provincia de Shandong estaban en las listas para obtener permiso de un segundo hijo. Pero $80 \%$ de los nacimientos extra fueron en aldeas que no tenían permiso. En Guangdong, donde también hay permisos para tener más de un hijo, el número de terceros o más hijos aumentó de 260900 en 1985 a 410400 en 1986. Para 1987 el número de mujeres entre 30 y 49 años que tenían más de tres hijos fue $62.5 \%$ del total (China Daily, 1 de julio de 1987).

A pesar de todos los contratiempos, las autoridades chinas no han abandonado la batalla. La Comisión Estatal de Planificación Familiar ha redoblado esfuerzos y ha organizado redes aún más extensas para promover la educación en la población. Entre la Comisión Estatal de Planificación Familiar y el pueblo están las Asociaciones de Planificación Familiar. En ellas trabajan 4.3 millones de personas que hacen trabajo de promoción entre más de $500 \mathrm{mi}$ llones de jóvenes en edad fértil. Los promotores hacen proselitismo sobre la política de un solo hijo, ayudan a las parejas a elegir métodos anticonceptivos, etc. Para que los promotores sean más efectivos y menos impopulares, se organizan cursos de adiestramiento y de capacitación. Últimamente se han ofrecido cursos de educación sexual tanto a médicos como a promotores de planificación familiar (China Daily, 23 de mayo de 1988). También se ha cambiado la retórica oficial que atribuía los fracasos de las campañas a "la mentalidad feudal" de los campesinos y se reconocen las razones económicas, psicológicas y prácticas para la resistencia a reducir su fecundidad (Wu, Zheng y Zhou, 1981, pp. 45-46) y se están tomando medidas para acallar temores. Por ejemplo se están estableciendo asilos para ancianos que tranquilizarán a los que temen llegar a la vejez sin apoyo y ser una carga demasiado pesada para un solo hijo.

Ha sido importante en los últimos años el papel de la Federación de Mujeres. Este organismo de masas, en los primeros años de la República Popular China, fue muy importante por la ayuda que brindó a las mujeres para hacer valer sus derechos recientemente adquiridos. Con la Revolución Cultural entró en una etapa de inacción al igual que todos los demás organismos de esta índole. Ahora ha vuelto a surgir como un foro de ayuda a la mujer (Kane, 1985, p. 89). La Federación de Mujeres está estrechamente vinculada a la Planificación Familiar a través de sus oficinas regionales y sus representantes en entidades de trabajo. También tiene contactos con áreas rurales donde se lleva a cabo investigación y se procura ayudar a la mujer campesina contra abusos y 
maltratos (entre otros, los que son consecuencia de las campañas de planificación familiar].

Si en el campo existen aún graves problemas, en la ciudad ha sido mucho más fácil convencer al pueblo de disminuir el número de hijos. Un análisis preliminar de $\mathbf{5 4}$ de las entrevistas realizadas entre julio y noviembre de 1987 en nuestra investigación de campo en las áreas urbanas más representativas de China, nos hace concluir que en principio la política de control de la natalidad en la República Popular China ha tenido éxito en las ciudades. La disminución del número de hijos en relación con las familias de origen es evidente, como lo demuestra el cuadro 9.

Claro que la drástica disminución de la natalidad que se desprende del cuadro anterior no puede ser vista sólo como un éxito de la política de población. El elemento general más importante que hay que tener en cuenta en el análisis del cuadro es que se trata en su mayoría de una población de urbanización reciente, es decir, la mayoría de las familias de origen eran campesinas.

Otro elemento que según nuestra investigación ha colaborado de manera indirecta, pero para nosotros determinante, en la planificación familiar en las ciudades chinas ha sido la situación crítica de las condiciones de habitación. El sobrepoblamiento de las ciudades chinas es un fenómeno que se viene experimentando descle.la crisis del imperio en el siglo XVIII y que se agudizó con la guerra civil en las décadas de 1920, 1930 y 1940. Aunque la migración campo-ciudad disminuyó considerablemente a partir de 1949, no puede decirse que haya desaparecido por completo. Los proyectos de construcción de vivienda que emprendió la República Popular fueron muy limitados en la inversión. Además, influidos probablemente por conceptos de socialización y también por la limitación de recursos, predominó la construcción de edificios de cuartos con servicios compartidos. En realidad no fue sino has- ta 1985 cuando el gobierno chino mostró interés por el problema de la vivienda. En ese año se realizó la primera encuesta sobre vivienda urbana.

Hasta ahora tanto la construcción como la propiedad de la vivienda en las ciudades ha sido cuestión del Estado y de las organizaciones colectivas de trabajo, y son rentadas a precios muy bajos a las familias. La inversión del Estado en vivienda ha sido muy baja: entre 1949 y 1979 fue de $0.77 \%$ del PNB, en 1979 aumentó a $2.07 \%$ y en 1985 a $3.74 \%$. Según una encuesta hecha por el gobierno en 1986, había un promedio de $6 \mathrm{~m}^{2}$ por persona en las áreas urbanas. Lógicamente hay variaciones regionales; según nuestra investigación, las ciudades con menos espacio habitacional fueron las del noreste (Harbín en particular). 
Nuestros entrevistados viven en un promedio de $30 . \mathrm{m}^{2}$ por familia, en muchos casos con servicios compartidos. Uno de los casos más críticos lo encontramos en Xian: un maestro de escuela que vive en una habitación con su mujer y dos hijas, debe separarla con una cortina para encontrar un poco de privacía. La mayoría de nuestros entrevistados debió pasar los primeros años de su matrimonio con parientes o en una sola habitación en un edificio de su unidad de trabajo. A las personas que tienen más tiempo en su trabajo se les suele asignar un poco más de espacio y otros servicios. Tanto la prosperidad económica de las entidades de trabajo como los "contactos" o el buen comportamiento de los empleados suele reflejarse en las condiciones de habitación. Últimamente la mayor disponibilidad de bienes de consumo ha atiborrado los pequeños cuartos-habitación chinos de objetos que agravan más la crisis de espacio.

Entre nuestros entrevistados el problema de la habitación fue muchas veces una limitación esgrimida para explicarnos por 'qué tenían pocos hijos, en contraste con lo que dicta la tradición en China. También, tanto hombres como mujeres señalaron el alto costo de criar y educar a un niño así como el tiempo que se le debe dedicar como otra razón para tener un solo hijo. Podríamos entonces decir que en la decisión de la planificación familiar en las ciudades también pesan los argumentos individuales. El análisis del número de hijos entre nuestros entrevistados y la correlación de este dato con la edad nos muestra los efectos de las políticas gubernamentales sobre la planificación familiair. De las 54 familias analizadas, 23 , o sea más de $42 \%$, tienen un solo hijo; sin embargo, es interesante notar que de las 23 familias con un solo hijo, una mayoría aplastante, 18 de ellas, tienen un hijo varón. Lo que nos remite a una combinación de política de un solo hijo con un factor tradicional: la ventaja de que éste sea del sexo masculino. Ya habíamos señalado la preferencia por el hijo varón; sin embargo es necesario recalcar la incidencia de esta preferencia en la planificación familiar y sus consecuencias. Ya para 1982 la mayoría de las familias que habían firmado los compromisos de tener un solo hijo tenían un hijo varón (Arnold y Liu, 1986, pp. 221-244). Naturalmente en este fenómeno hay variaciones regionales, así como en relación con el nivel educativo y la ocupación, que son los estratos que se pueden manejar en China hasta ahora. Sin embargo, insistimos en que el peso de los factores ideológicos sigue siendo determinante. Tres autores, Kang Mingcun, Pang Shugui y Gu Zushan, del Colegio Médico del distrito.Shihezi de la Región Autónoma de Xinjiang, en un artículo aparecido en la revista-sobre población más importante de China concluyen que: "tener 
CUADRO 9

Comparación entre el número de hijos de familias actuales con el de sus familias de origen en seis ciudades de China (1987)

\begin{tabular}{ccc}
\hline $\begin{array}{c}\text { Clave de } \\
\text { la familia } \\
\text { entrevistada }\end{array}$ & $\begin{array}{c}\text { Número de hijos } \\
\text { de la familia } \\
\text { entrevistada }\end{array}$ & $\begin{array}{c}\text { Número de hijos } \\
\text { de la familia } \\
\text { de origen }\end{array}$ \\
\hline HBM48 & 3 & 7 \\
HBH34 & 1 & 4 \\
HBH42 & 2 & 8 \\
HBM53 & 2 & 8 \\
HBM30 & 1 & 4 \\
HBM39 & 1 & 7 \\
HBM45 & 2 & 5 \\
HBH41 & 2 & 4 \\
JNH50 & 2 & 6 \\
JNM55A & 2 & 3 \\
JNM36 & 1 & 4 \\
JNH38 & 1 & 6 \\
JNH57 & 3 & No respondió \\
JNH32 & 1 & 4 \\
JNM55B & 3 & 6 \\
XAM50 & 2 & 8 \\
XAM42 & 2 & 5 \\
XAM35 & 1 & 3 \\
XAH53 & 2 & 5 \\
XAM53 & 4 & 7 \\
XAM40 & 1 & 6 \\
XAH53 & 3 & 2 \\
XAM49 & 2 & 3 \\
XAM50 & 3 & 3 \\
BJH50 & 3 & 9 \\
BJH53 & 3 & 4 \\
BJH62 & & \\
BJM50 & 3 & 5
\end{tabular}

más hombres que mujeres es favorable para la patria y para la nación. Debido a factores fisiológicos, sólo los hombres pueden llevar a cabo trabajos relativos a la seguridad y construcción del Estado, y además más hombres que mujeres están expuestos a muertes accidentales Por lo tanto en la composición de la población de un país, tener más hombres que mujeres es beneficioso para la seguridad del Estado y para la prosperidad nacional" (Kang, Pang y Gu, 1981, p. 45]. Esto es presentado como conclusión de un informe cuyo resultado es una proporción de 112 hombres por cada 100 mujeres entre los hijos únicos en el distrito Shihezi, proporción 
CUADRO 9

[Continuación]

\begin{tabular}{ccc}
\hline $\begin{array}{c}\text { Clave de } \\
\text { la familia } \\
\text { entrevistada }\end{array}$ & $\begin{array}{c}\text { Número de hijos } \\
\text { de la familia } \\
\text { entrevistada }\end{array}$ & $\begin{array}{c}\text { Número de hijos } \\
\text { de la familia } \\
\text { de origen }\end{array}$ \\
\hline BJH40 & 1 & 7 \\
BJH44 & 2 & 5 \\
BJM36 & 1 & 4 \\
BJM38 & 1 & 2 \\
BJH55 & 3 & 7 \\
BJH34 & 1 & 3 \\
BJM31 & 1 & 2 \\
BJH40 & 1 & 7 \\
BJH47 & 2 & 3 \\
BJH61 & 4 & 7 \\
NNM39 & 2 & 7 \\
NNH38 & 1 & 2 \\
NNM35 & 1 & 6 \\
NNM49 & 2 & 7 \\
NNH38 & 2 & 6 \\
NNM30 & 1 & 4 \\
NNH39 & 2 & 2 \\
NNH67 & 4 & 4 \\
NNH50 & 1 & 9 \\
SZM42 & 2 & 4 \\
SZM43 & 3 & 4 \\
SZM31 & 1 & 3 \\
SZM37 & 1 & 4 \\
SZH33 & 1 & 7 \\
SZM33 & 3 & 6 \\
SZH48 & 1 & 3 \\
\hline
\end{tabular}

* Esta clave está compuesta por la inicial de la ciudad donde vive el entrevistado: HB(Harbín), JN(Jinan), XA(Xian), BJ(Beijing), NN(Nanning) y SZ(Shenzhen), el sexo: $H(h o m b r e)$ y $M(m u j e r)$ y la edad del entrevistado.

que es más alarmante aún en las áreas urbanas del distrito, 121 a 100, considerando que el promedio mundial es de 103-108 a 100 [Davin, 1985, pp. 62-63).

Otro de los elementos que hay que destacar en los casos hasta ahora analizados por nosotros es que de las 23 personas que tienen un solo hijo, 21 tienen menos de 42 años, y 18 menos de 40. Esto nos indica la tendencia entre personas socializadas desde 1949 en las ciudades de seguir en cierta forma la planificación de los nacimientos. De igual manera podemos apreciar que de las trece familias que tienen tres o más hijos, diez tienen tres y tres tienen 
cuatro hijos, y si vemos la edad de los padres, una corresponde a un informante de 43 años que tiene tres hijos, dos a informantes de 48 años, que tienen 3 hijos cada uno y los diez restantes corresponden a personas entre 50 y 67 años. De nuevo pensamos que esto refuerza nuestra apreciación de que la aceptación de la planificación familiar es más probable entre las personas de menor edad. También apreciamos la correlación entre el nivel educativo y la aceptación de la política de un solo hijo, lo cual viene a corroborar trabajos ya hechos en China en ese sentido (Tang, 1985, pp. 26-27).

En el campo la situación es diferente y aunque las condiciones de habitación son todavía insuficientes, sobre todo en relación con los servicios, el área disponible para cada habitante es mayor que en las ciudades y está en aproximadamente $14 \mathrm{~m}^{2}$ por habitante. Desde la implantación del sistema de responsabilidad familiar la construcción de víviendas en el campo ha recaído totalmente sobre los campesinos; ello ha provocado un auge de construcción que ha comenzado a preocupar al gobierno por la ocupación de tierras cultivables y a los arquitectos por la proliferación de estilos exóticos entre los recién enriquecidos campesinos chinos. Ya se han dictado normas de construcción que incluyen división espacial, higiene y estética. Al contrario de las ciudades la habitación en el campo no es una limitante para la familia numerosa en China.

En cuanto al sexo del hijo único, en la ciudad ha tenido mayor éxito la campaña de convencimiento de que una niña es igual o a veces mejor que un niño. Nuestros entrevistados afirmaban preferir a veces tener hijas porque "son más cariñosas" y "más dóciles". Quienes expresaban estar contentos con sus hijas siempre daban la explicación del porqué, lo que se consideraba obvio en el caso de un varón. Por ejemplo, una obrera de 36 años a la que se le pregunta si está contenta con su hijo varón, responde: "Sí, claro que estoy feliz". " Ella no necesita justificación alguna. La preocupación por la vejez es también menor puesto que en las ciudades hay jubilación de 80 a $100 \%$ del salario. De nuestros entrevistados, los que tenían padres en áreas urbanas decían no tener obligaciones económicas hacia ellos, mientras que los que aún tenían a sus padres en el campo manifestaron deber ayudarlos económicamente, aunque esta ayuda aún se reparte entre varios hermanos y la carga no es tan pesada.

Para terminar hay que decir unas palabras sobre el tema de la eugenesia. En China no había tradicionalmente un conocimiento exacto de cuántos niños nacían con defectos físicos o mentales.

${ }^{4}$ Entrevista BJM36. 
Sin embargo, con la política de un solo hijo se suscitó una preocupación por la eugenesia. Lo que esto significa es que ya que las parejas tendrán un solo hijo, es preciso procurar que este hijo sea sano y no tenga defectos hereditarios o ambientales (Sun, 1981, pp. 144149]. Como además, según las leyes de excepción, las parejas que tienen un primer hijo con mala salud física o mental pueden pedir permiso para tener otro, las autoridades chinas prefieren impedir el nacimiento de un niño con defectos (Banister, 1987, p. 222).

En muchas ciudades el examen prenupcial es obligatorio y en él se pretende detectar enfermedades hereditarias u otras razones que impiden a la gente casarse o al menos procrear. Hay varias prohibiciones. Por ejemplo, no pueden casarse parientes colaterales hasta en la tercera generación, retrasados mentales, personas con enfermedades venéreas, enfermos mentales o maníacos depresivos (a menos de que puedan probar que su enfermedad ha sido curada], enfermos de tuberculosis, lepra, enfermedades infecciosas graves y defectos graves de corazón, hígado o rin̄ón. Los sordomudos, las personas con defectos físicos hereditarios, los ciegos, etc., pueden casarse pero no se les permite tener hijos (China Daily, 8 de abril de 1988).

La lista es larga y las prohibiciones son claras. Sin embargo, el matrimonio en China es algo universal. La gente prefiere obviar los detalles y siempre hay posibilidad de encontrar pareja aún en los casos difíciles. El examen prenupcial es algo aún muy limitado en áreas desarrolladas, y por eso si los contrayentes no lo manifiestan no hay manera de detectar los problemas (Banister, 1987, p. 225].

En cuanto a la amniosíntesis, aunque es conocida en China y se usa en algunas grandes ciudades para detectar malformaciones en el feto, aún no es asequible para la mayoría de la población. En este renglón, es posible que las autoridades chinas eviten la difusión del método de amniosíntesis puesto que así se puede también detectar el sexo del niño. Ya se conocen casos de abortos de mujeres que se enteran a través de pruebas de ultrasonido del sexo de sus hijos, y el alarmante desbalance entre niños (124) y niñas [100) en un distrito de Zhujiang en 1988 se cree que obedece a esta razón (China Daily, 7 de diciembre de 1988). Con la preferencia que existe en China por tener varones, al conocer el sexo del niño es previsible que mucha gente abortaría si supiera que es niña. Las consecuencias en cuanto al desequilibrio futuro entre las tasas de hombres y mujeres serían desastrosas. Esta situación es conocida ya, por ejemplo en la India. Aún así, la parte positiva de la eugenesia y el aspecto que se ha desarrollado más en China es el del cuidado y la educación prenatal que si bien no es universal, es 
cada día más difundida. En eso también se involucra la Federación de Mujeres, además de las promotoras de planificación familiar y de las personas encargadas de las Oficinas de Asuntos Familiares en las fábricas y otras entidades de trabajo.

\section{Conclusiones}

A pesar del relativo éxito de la campaña de planificación familiar, el gobierno chino no ha alcanzado las metas que se propuso. Así, la meta para fines del siglo que fue fijada a principios de esta década en 1.2 mil millones y que luego fue modificada por "alrededor de" 1.2 mil millones, se ha extendido a 1.27 mil millones. Según las estadísticas más recientes, 32.3 millones de parejas han expresado que desean tener sólo un hijo, y 78\% usan algún método anticonceptivo. Esos 32.3 millones sólo representan a 18\% de las parejas en edad de procrear, y si lo desglosamos рог áreas sería: $36 \%$ en las áreas urbanas y $11 \%$ en las rurales (China Daily, 1 de noviembre de 1988). Sin embargo, sigue sabiéndose de avances importantes. Según la última encuesta sobre fecundidad, realizada por la Comisión Estatal de Planificación Familiar en julio de 1988, la tasa de natalidad bajó a 8.84 por mil en la primera mitad de ese año; es decir, bajó en 1.2 por mil comparado con el mismo periodo en 1987 (China Daily, 28 de octubre de 1988). Sin embargo, hay que analizar estas estadísticas alentadoras en el contexto general; en el informe del Buró Estatal de Estadísticas sobre 1987 los resultados no eran muy alentadores, pues arrojó resultados negativos sobre aumento de matrimonios tempranos y tasa de natalidad de mujeres entre 15'y 19 años (Beijing Review, núm. 49, 1988, pp. 27-28).

El gran problema que se plantea ahora y en los cinco años futuros es que están llegando a la edad de procrear los jóvenes que nacieron en la explosión poblacional que se produjo por los matrimonios apresurados de los años álgidos de la Revolución Cultural (1966-1969); de allí la importancia de acentuar, en este momento, la propaganda y la educación sobre matrimonio tardío y anticonceptivos. Por otro lado, aunque en China se están estudiando los problemas de los hijos únicos desde el punto de vista psicológico (Chen, 1986, pp. 105-111) y se está haciendo algún acercamiento hacia los padres que nada más pueden tener un hijo, los efectos a nivel ideológico aún no son claros. En China se ha estudiado el problema psicológico de los padres como algo que tiene que ver con "necesidad reproductiva" vinculada al bienestar [Chen, 1983, pp. 24-28). Sin embargo, no se han estudiado los efectos sobre la población de los cambios en los patrones de reproducción que por 
siglos dieron al individuo su ubicación en el mundo y un sentido general de la trascendencia de su propia vida.

\section{Bibliografia}

Arnold, Fred y Liu Zhaoxiang, "Sex Preference, Fertility, and Family Planning in China", Population and Development Review, vol. 12, núm. 2, 1986.

Banister, Judith, China's Changing Population, Stanford, Stanford University Press, 1987.

Beijing Informa.

Beijing Review.

Benítez, Asunción, "Infanticidio femenino en China", Estudios de Asia y Africa, vo]. XXI, núm. 3, 1986, pp. 398-412.

"Constitución de la República Popular China" en Beijing Informa, núm. $52,1982$.

Croll, Elizabeth, "Introduction: Fertility Norms and Family Size in China", en Elizabeth Croll, Delia Davin y Penny Kane, China's Ore Child Family Policy, Nueva York, St. Martin's Press, 1985.

Chen Jialin, "Problemas psicológicos en el trabajo de planificación familiar", Renkou Yanjiu, núm. 6, 1983.

Chen Kewen, "Sobre la sociabilidad de los hijos únicos", Shehui Yanjiu, núm. 2, 1986.

Chen Pi-Chao, "Birth Control Methods and Organization in China", en Elizabeth Croll, Delia Davin y Penny Kane, China's One Child Family Policy, Nueva York, St. Martin's Press, 1985.

Chen Xiangmin, "The One Child Population Policy Modernization and the Extended Chinese Family", en Journal of Marriage and the Family, vol. 47, núm. 1, febrero, 1985.

China Daily.

Davin, Delia, "The Single-Child Family Policy in the Countryside" en Elizabeth Croll, Delia Davin y Penny Kane, China's One Child Family Policy, Nueva York, St. Martin's Press, 1985.

Greenhalgh, Susan, "Shifts in China's Population Policy, 1984-1986: Views from the Central, Provincial and Local Levels", Population and Development Review, vol. 12, núm. 3, 1986.

Kane, Penny, The Second Billion, Australia, Penguin Books, 1987.

"The Single-Child Family Policy in the Cities", en Elizabeth Croll, Delia Davin y Penny Kane, China's One Child Family Policy, Nueva York, St. Martin's Press, 1985.

Kang Mingcun, Pang Shugui y Gu Zushan, "Encuesta sobre la proporción de los hijos únicos en el distrito Shihezi, Región Autónoma de Xinjiang", Renkou Yanjiu, núm. 2, 1981.

Kaufman, Joan, A Billion and Counting, San Francisco, San Francisco Press, 1983.

"Ley de Matrimonio de la República Popular China", en Beijing Informa, Isúm. 11, 1981. 
New China's Population, Nueva York, MacMillan Publishing Co., 1988. Peng Xizhe, "Demographic Consecuences of The Great Leap Forward", en Population and Development Review, vol. 13, núm. 4, 1987.

The Population Research Office, Anhui University, "A Survey of OneChild Families in Anhui Province in China", en Studies in Family Planning, vol. 13, núm. 6/7, junio/julio, 1982.

Renmin Ribao.

Sun Nianhu, "La eugenesia y e] examen prenatal", Simposio sobre la Ciencia de la Población China (en chino), Beijing, Editores Académicos de China, 1981.

Tang Dechun, "Impacto del nivel educativo sobre la fertilidad de las mujeres", Renkou Yanjiu, núm. 6, 1985.

Tien Yuan, "Provincial Fertility Trends and Patterns", en Elizabeth Croll, Delia Davin y Penny Kane, China's One Child Family Policy, Nueva York, St. Martin's Press, 1985.

Wu Wenhua, Zheng Wenxian y Zhou Shanpu, "Cómo opinan los campesinos sobre la política de un solo hijo", en Renkou Yanjiu, núm. 4. 1981.

Yang Zhelong y Wang Shikui, "Los matrimonios con una hija única deben tener elogio, apoyo y premios", Renkou Yanjiu, núm. 5, 1981.

Yu Yanfei, "La publicidad de la planificación familiar debe basarse en servir a las masas", Renkou Yanjiu, núm. 6, 1985. 